\title{
AKR1B10 promotes breast cancer cell proliferation and migration via the $\mathrm{PI3K} / \mathrm{AKT} / \mathrm{NF}-\mathrm{KB}$ signaling pathway
}

Jiayao Qu

The First People's Hospital of Chenzhou

Jia Li

The First People's Hospital of Chenzhou

Rongzhang He

The First People's Hospital of Chenzhou

Xiangting Liu

The First People's Hospital of Chenzhou

\section{Ke Gong}

The First People's Hospital of Chenzhou

\section{Lili Duan}

The First People's Hospital of Chenzhou

\section{Weihao Luo}

The First People's Hospital of Chenzhou

\section{Zheng Hu}

The First People's Hospital of Chenzhou

dixian luo ( $\square$ luodixian_2@163.com )

National \& Local Joint Engineering Laboratory for High-through Molecular Diagnosis Technology https://orcid.org/0000-0001-6155-8137

\section{Primary research}

Keywords: AKR1B10, PI3K/AKT, NF-KB, Proliferation, Migration

Posted Date: August 12th, 2020

DOI: https://doi.org/10.21203/rs.3.rs-52495/v1

License: (1) (1) This work is licensed under a Creative Commons Attribution 4.0 International License. Read Full License 
Version of Record: A version of this preprint was published at Cell \& Bioscience on August 21st, 2021. See the published version at https://doi.org/10.1186/s13578-021-00677-3. 


\section{Abstract}

\section{Backgroud}

Aberrant expression of Aldo-Keto reductase family 1 member B10 (AKR1B10) has been observed during the progression of some human carcinomas. However, the expression pattern and clinical relevance of AKR1B10 in breast cancer (BC) need clarification.

\section{Methods}

The relationship between the high expression of AKR1B10 and the overall prognosis and disease-free survival of breast cancer patients was analyzed by Kaplan-Meier Plotter database. Breast cancer cell lines MCF-7/AKR1B10 stably overexpressing AKR1B10 and breast cancer cell lines BT-20/shAKR1B10 that knock down AKR1B10 were constructed, respectively. RT-qPCR, Western blot and immunohistochemistry were used to detect the expression of AKR1B10 in breast cancer and its normal tissues. CCK8 cell proliferation assay and cell scratch test were used to detect the proliferation and migration of breast cancer cells. Western blot was used to detect the expression of proliferation-related proteins cyclinD1, cmyc, survivin and EMT-related proteins twist, snail, slug, ZEB1, E-cadherin, PI3K, p-PI3K, AKT, p-AKT, IKBa, p-IKBa, NF-KB p65, and p-NF-KB p65 proteins in breast cancer cells. The PI3K inhibitor LY94002 was used to treat MCF-7 cells to detect PI3K/AKT/NF-KB signal cascade protein Expression, and expression of NF$\mathrm{KB}$ p65 in nucleoproteins and plasma proteins.

Results

In this study, we found that AKR1B10 expression was higher in BC tissue compared to paired noncancerous tissue. The expression of AKR1B10 positively correlated with lymph node metastasis, tumor size, Ki67 expression, and p53 expression, but inversely correlated with overall and disease-free survival rates. Gene Ontology (GO) analysis showed that AKR1B10 was closely related to cell proliferation. Overexpression of AKR1B10 facilitated proliferation and migration of BC cells in vitro in association with induction of epithelial-mesenchymal transition. Conversely, knockdown of AKR1B10 inhibited these effects. Mechanistically, silencing AKR1B10 reduced the phosphorylation of PI3K, AKT, and NF-KB p65, whereas AKR1B10 overexpression activated these signaling molecules. Indeed, PI3K inhibition attenuated NF-kB p65 nuclear localization.

\section{Conclusions}

Our results demonstrate that AKR1B10 promotes proliferation and migration of $\mathrm{BC}$ cells and represents a novel prognostic indicator as well as a potential therapeutic target in BC.

\section{Backgroud}

Breast cancer (BC), originating from breast epithelial tissue, is one of the most frequently occurring malignant tumors of female genitalia[1]. Epidemiological studies suggest that the number of female BC 
patients increases by 304,000 each year in China, and the incidence rate continues to increase annually[2]. The prognosis for patients remains poor, in spite of significant progress in diagnosis and treatment, especially in triple-negative $\mathrm{BC}[3,4]$. Therefore, better insight into the mechanism of $\mathrm{BC}$ would be helpful for development of more effective diagnostic or therapeutic strategies.

Aldo-Keto reductase family 1 member B10 (AKR1B10), also known as Aldose reductase like protein-1 (ARL-1), is a member of the human aldo-keto reductase (AKR) superfamily which protects cells by reducing aldehyde ketone carbonyl compounds to alcohols[5]. AKR1B10 plays a central role in cancer lipid metabolism by governing the synthesis of lipids through stabilizing acetyl coenzyme-A carboxylase a[6]. In recent studies, mRNA levels of AKR1B10 were detected in several types of tumors[7-9]. In hepatocellular carcinoma (HCC) patients, the high expression of AKR1B10 positively correlated with poor prognosis[10]. In patients with BC, high expression of AKR1B10 is associated with drug resistance[11]. However, little is known about the detailed function and underlying molecular mechanism of AKR1B10 in the pathology of $\mathrm{BC}$.

In our previous study, we showed that PI3K inhibitors block cell proliferation in BC cells overexpressing AKR1B10, which suggested that in BC, AKR1B10 may regulate the AKT signaling pathway. We also noted that AKR1B10-overexpression increased the protein levels of Snail. Based on these findings, we comprehensively investigated the effects of AKR1B10 and its' associated mechanisms in BC, which provide a novel foundation for future $\mathrm{BC}$ diagnosis and treatment.

\section{Methods}

\section{Patients and tissue specimens}

Tumor and adjacent normal tissues were obtained from 33 BC patients in The First People's Hospital of Chenzhou between 2013-2016. None of the patients underwent chemotherapy, radiotherapy or immunotherapy prior to surgery. Tumor, Node, Metastasis (TNM) staging was performed according to the 8th edition of American Joint Committee on Cancer (AJCC) staging system. The study was approved by the Ethics Committee of The First People's Hospital of Chenzhou and informed consent was obtained from all patients.

\section{Cell culture and treatments}

The human BC cell lines MCF-7(RRID:CVCL_0031) and BT-20(RRID:CVCL_0178) were purchased from the Shanghai Institute of Biochemistry and Cell Biology, Chinese Academy of Sciences (Shanghai, China). All human cell lines have been authenticated using short-tandem repeats (STR) profiling within the last three years. All experiments were performed with mycoplasma-free cells. Overexpression stable cell line and knockdown stable cell line were established as previously described[8] in our laboratory. Wherever mentioned, cells were treated with $30 \mu \mathrm{M}$ and/or $50 \mu \mathrm{M}$ of the PI3K inhibitor LY294002 (CST) for $48 \mathrm{~h}$.

\section{Immunohistochemistry (IHC)}


IHC staining was conducted as previously described[12]. A rabbit polyclonal antibody against AKR1B10 (1:100, self-prepared) was used in our work. The IHC score was calculated by multiplying the percentage of positive cells with the intensity of staining. The intensity of IHC staining was designated as: - (no staining), + (weak staining), ++ (moderate staining), and +++ (strong staining). The percentage of stained cells was determined as: 1 (1-25\%), $2(26-50 \%), 3(51-75 \%)$, and $4(76-100 \%)$.

\section{Quantitative real-time RT-PCR}

Briefly, total RNA was extracted from cell lysates and breast normal/tumor tissues using RNA TRIzol Reagent (Invitrogen, USA) according to manufacturer's instructions. Reverse transcription was performed using the GoScript Reverse Transcription System (Promega, USA) following manufacturer's protocols. RTPCR reactions were performed using SYBR Premix Ex Taq II (Takara, Japan) in a Light Cycle480 RealTime PCR Detection System (Roche, Germany) following the manufacturer's instructions. The relative mRNA levels were normalized against GAPDH using the $2^{-\Delta \Delta} \mathrm{Ct}$ formula. The primer sequences were as follows: GAPDH forward-ACCACAGTCCATGCCATCAC; reverse-TCCACCCTGTTGCTGTA; AKR1B10 forward-GCTGAGCTATCTGGACGTCT; reverse, CGTTACAGGCCCTCCAGTTT.

\section{Cell proliferation assay}

Cell Counting Kit-8 (CCK-8, Beyotime, China) was used to detect cell proliferation. Briefly, a total of $1 \times 10^{3}$ cancer cells were seeded in each well of a 96-well plate and a CCK-8 kit was used every $24 \mathrm{~h}$. The absorbance was measured $24 \mathrm{~h}$ later at $450 \mathrm{~nm}$, and cell growth curves were generated.

\section{Wound healing assay}

Cells were seeded and cultured in six-well plates with serum free medium for $24 \mathrm{~h}$. Wounds were created by introducing scratches in the monolayer of cells using $100 \mu \mathrm{L}$ pipette tips. The medium was then replaced with fresh medium. Plates were washed twice with fresh medium to remove non-adherent cells after the cells had been cultured for $0,48 \mathrm{~h}$, and then photographed. Finally, the distances between wound edges were measured.

\section{Bioinformatics analysis}

The Kaplan Meier-plotter database (http://www.kmplot.com) was used to evaluate the relationship between AKR1B10 expression and overall or disease-free survival rates in patients with BC. Coexpedia (http://www.coexpedia.org)[13] was used for AKR1B10 Gene Ontology (GO) term analysis.

\section{Western blotting}

Western blotting analyses were performed as previously described[14]. The primary antibodies used in this study are listed in Table $\mathbf{S 1 .}$

\section{$\mathrm{PIP}_{3}$ ELISA assay}

$\mathrm{PIP}_{3}$ concentrations were measured using the enzyme-linked immunosorbent assay (ELISA). Briefly, cells were rinsed with PBS, detached by scraping, collected by centrifugation, and disrupted by ultrasonic 
treatment. The blank well, standard well and the sample well were set, respectively; $40 \mu \mathrm{l}$ sample dilution buffer and $10 \mu \mathrm{l}$ sample solution was added in the test well. $100 \mu \mathrm{l}$ of enzyme labeling reagent was added to each well, except for blank wells. After incubation for 30 minutes, absorbance was measured at $450 \mathrm{~nm}$ and $\mathrm{PIP}_{3}$ concentration was calculated using a standard curve.

\section{In vivo tumor xenograft experiments}

A total of 12 nude mice were randomly divided into 2 groups of 6 each for our experiments. In brief, $5 \times$ $10^{6}$ BT-20/scramble cells and BT-20/shAKR1B10 cells were injected into the mammary fat pad of the 2 groups respectively. Four weeks later, the mice were sacrificed, and the xenograft tumor tissue was weighed. The study protocol complied with the ARRIVE guidelines and was carried out by following the National Institutes of Health guide for the care and use of Laboratory animals.

\section{Statistical analysis}

Statistical Package for the Social Sciences (SPSS) V.20. For Windows was used to run statistical analyses. The Student's $t$ test and ANOVA were used to compare the statistical differences between groups. A significance value of $P<0.05$ was considered to indicate a significant difference.

\section{Results}

\section{AKR1B10 upregulation in BC tissues is associated with clinicopathological features}

Curits breast dataset data including 14 cases of ductal carcinoma in situ and 144 cases of normal breast tissue were obtained from the Oncomine database. AKR1B10 mRNA levels were significantly upregulated in BC tissues compared to normal tissues (Fig. 1A). In our work, we analyzed AKR1B10 mRNA in 8 pairs of fresh BC tissue/normal tissue by qRT-PCR as well as AKR1B10 protein in 4 pairs of fresh BC tissue/normal tissue through western blotting. Both mRNA and protein levels of AKR1B10 were significantly higher in tumor tissues than adjacent non-tumor counterparts (Fig. 1B-D). Furthermore, immunohistochemistry (IHC) was used to examine AKR1B10 expression in $33 \mathrm{BC}$ samples and paired adjacent non-tumor tissue. AKR1B10-positive staining was significantly higher in cancer tissues than normal breast tissues (Fig. 1E-F). These results demonstrate that AKR1B10 is overexpressed in BC tissues.

Next, the association between AKR1B10 expression and clinicopathological characteristics of patients with BC was analyzed. The protein levels of AKR1B10 markedly correlated with lymph node metastasis $(p=0.016)$, tumor size $(p=0.010)$, Ki67 expression $(p=0.036)$, and $p 53$ expression $(p=0.000)$ (Table 1$)$.

Kaplan-Meier survival analysis showed that AKR1B10 high patients had markedly lower overall survival (OS, $p=0.0061)$ and disease-free survival (DFS, $p=0.014$ ) rates compared to AKR1B10 low $B C$ patients (Fig. 1G-H). Furthermore, we noticed that AKR1B10 high triple-negative BC patients had a significantly 
lower DFS $(p=0.0011)$ rates compared to AKR1B10 low triple-negative BC patients (Fig. 1I). The above results indicate that AKR1B10 may play an important role in BC development and pathology. 
Table 1

The relationship between AKR1B10 expression and clinicopathological features of patients with breast cancer

\begin{tabular}{|c|c|c|c|c|c|c|}
\hline \multirow[t]{2}{*}{ clinical parameters } & \multirow[t]{2}{*}{$\mathbf{n}$} & \multicolumn{2}{|c|}{ AKR1B10 levels (IHC) } & \multirow[t]{2}{*}{$x^{2}$} & \multirow[t]{2}{*}{$\mathbf{R}$} & \multirow[t]{2}{*}{$\mathbf{P}$} \\
\hline & & $\leq 4$ & $>4$ & & & \\
\hline \multicolumn{7}{|l|}{ age } \\
\hline$<50$ & 34 & 23 & 11 & \multirow[t]{2}{*}{1.035} & \multirow[t]{2}{*}{0.435} & \multirow[t]{2}{*}{0.317} \\
\hline$\geq 50$ & 29 & 16 & 13 & & & \\
\hline \multicolumn{7}{|l|}{ LN metastasis } \\
\hline Yes & 38 & 19 & 19 & \multirow[t]{2}{*}{5.755} & \multirow[t]{2}{*}{0.302} & \multirow[t]{2}{*}{0.016} \\
\hline no & 25 & 20 & 5 & & & \\
\hline \multicolumn{7}{|l|}{ tumor diameter } \\
\hline$\leq 2$ & 20 & 17 & 3 & \multirow[t]{2}{*}{6.628} & \multirow[t]{2}{*}{0.320} & \multirow[t]{2}{*}{0.010} \\
\hline$>2$ & 43 & 22 & 21 & & & \\
\hline \multicolumn{7}{|l|}{ Ki67 } \\
\hline$\leq 20 \%$ & 29 & 22 & 7 & \multirow[t]{2}{*}{4.439} & \multirow[t]{2}{*}{0.265} & \multirow[t]{2}{*}{0.036} \\
\hline$>20 \%$ & 34 & 17 & 17 & & & \\
\hline \multicolumn{7}{|l|}{ P53 } \\
\hline$\leq 40 \%$ & 29 & 25 & 4 & \multirow[t]{2}{*}{13.457} & \multirow[t]{2}{*}{0.462} & \multirow[t]{2}{*}{0.000} \\
\hline$>40 \%$ & 34 & 14 & 20 & & & \\
\hline \multicolumn{7}{|l|}{ ER } \\
\hline+ & 31 & 21 & 10 & \multirow[t]{2}{*}{0.882} & \multirow[t]{2}{*}{0.118} & \multirow[t]{2}{*}{0.356} \\
\hline- & 32 & 18 & 14 & & & \\
\hline \multicolumn{7}{|l|}{ PR } \\
\hline+ & 25 & 17 & 8 & \multirow[t]{2}{*}{0.653} & \multirow[t]{2}{*}{0.102} & 0.427 \\
\hline- & 38 & 22 & 16 & & & \\
\hline ERBB2 & & & & & & \\
\hline+ & 45 & 27 & 18 & 0.242 & -0.062 & 0.629 \\
\hline - & 18 & 12 & 6 & & & \\
\hline
\end{tabular}




\section{AKR1B10 promotes proliferation and migration of BC cells}

To further study the biological function of AKR1B10 in BC, we first established stable BC cell lines overexpressing AKR1B10 in MCF-7 cells by lentiviral infection. Similarly, stable knockdown of AKR1B10 was established by lentiviral-mediated expression of shRNA in BT-20 cells. Stable overexpression and knockdown was confirmed using RT-PCR and western blotting (Fig. 2A-B). The clinicopathological correlation analysis points to the role of AKR1B10 in the proliferation and metastasis of BC. We thus analyzed AKR1B10 genes through Gene Ontology (GO) terms in the coexpedia database. Gene function analysis of AKR1B10 indicated AKR1B10 was significantly associated with the terms 'cell cycle process', 'regulation of cell proliferation', 'regulation of cell cycle' etc. (Table 2). This further suggests that high expression of AKR1B10 is associated with cell proliferation. Next, we performed CCK8 proliferation assay and scratch wound assay. CCK8 assays showed that compared to the control group, overexpression of AKR1B10 promoted cell proliferation in MCF-7 cells, while knockdown reduced cell proliferation in BT-20 cells (Fig. 2C-D). The results from the scratch assay showed that AKR1B10 overexpression in MCF-7 cells markedly promoted the capacity for cell migration (Fig. 2E), as evidenced by faster wound closure.

Conversely, reduction of AKR1B10 in BT-20 cells suppressed cell migratory speed (Fig. 2F). These in vitro results demonstrated that AKR1B10 not only affects cell proliferation but also promotes migration in BC cells. 
Table 2

AKR1B10 Gene Ontology Functional Analysis

\begin{tabular}{|c|c|c|c|}
\hline GO enrichment & Term & & $\mathbf{P}$ \\
\hline $\begin{array}{l}\text { biological } \\
\text { process }\end{array}$ & G0:0007049 & cell cycle & 0.01653 \\
\hline $\begin{array}{l}\text { biological } \\
\text { process }\end{array}$ & G0:0042127 & regulation of cell proliferation & 0.03943 \\
\hline $\begin{array}{l}\text { biological } \\
\text { process }\end{array}$ & GO:0051726 & regulation of cell cycle & 0.04398 \\
\hline $\begin{array}{l}\text { biological } \\
\text { process }\end{array}$ & G0:0000083 & $\begin{array}{l}\text { regulation of transcription involved in } \mathrm{G} 1 / \mathrm{S} \\
\text { transition of mitotic cell cycle }\end{array}$ & 0.04766 \\
\hline \multicolumn{4}{|c|}{ Table S1: Primary antibodies used in this study } \\
\hline Target & Dilution & Company & $\begin{array}{l}\text { Catalog } \\
\text { Number }\end{array}$ \\
\hline AKR1B10 & $1: 500$ & Self-prepare & - \\
\hline c-myc & $1: 1000$ & CST & 18583 \\
\hline CyclinD1 & $1: 1000$ & CST & 55506 \\
\hline survivin & $1: 1000$ & Beyotime & AF1222 \\
\hline E-cadherin & $1: 1000$ & abcam & ab1416 \\
\hline ZEB1 & $1: 1000$ & abcam & ab228986 \\
\hline Snail & $1: 1000$ & abcam & ab229701 \\
\hline Slug & $1: 1000$ & abcam & ab51772 \\
\hline twist & $1: 1000$ & abcam & ab175430 \\
\hline NF-kB p65 & $1: 1000$ & CST & 8242 \\
\hline $\begin{array}{l}\text { phospho-NF-kB } \\
\text { p65 }\end{array}$ & $1: 500$ & CST & 3033 \\
\hline IKBa & $1: 1000$ & CST & 4814 \\
\hline phospho-ІкBa & $1: 500$ & CST & 2859 \\
\hline Total-PI3K & $1: 1000$ & CST & 4255 \\
\hline Phospho-PI3K & $1: 500$ & CST & 17366 \\
\hline Total-AKT & $1: 1000$ & CST & 4685 \\
\hline $\begin{array}{l}\text { phospho-AKT } \\
\text { (Ser473) }\end{array}$ & $1: 500$ & CST & 4060 \\
\hline
\end{tabular}




\begin{tabular}{|llll|}
\hline GO enrichment & Term & & P \\
\hline Histon H3 & $1: 1000$ & Beyotime & AF0009 \\
\hline B-actin & $1: 5000$ & Beyotime & AF0003 \\
\hline
\end{tabular}

Studies have shown that proliferation of cancer cells largely relies on proliferation-related proteins including c-myc, survivin and cyclinD1, which prompted us to investigate whether these regulators were involved in AKR1B10-induced proliferation of BC cells. As expected, c-myc, survivin and cyclinD1 were downregulated in BT-20 cells following AKR1B10 knockdown but upregulated in MCF-7 cells when AKR1B10 was overexpressed (Fig. 2G-H). It is well known that several Epithelial-mesenchymal transition (EMT)-related proteins play important roles in migration during tumor progression. We examined changes in the expression levels of the EMT-related proteins ZEB1, Snail, Slug, Twist and E-cadherin after AKR1B10-gene intervention in the BC cells by western blot. ZEB1, Snail, Slug, Twist expression increased and E-cadherin expression decreased following AKR1B10 overexpression in MCF-7 cells, whereas ZEB1 and Twist were downregulated following AKR1B10 knockdown in BT-20 cells (Fig. 2I-J). These data suggest that regulation of proliferation and EMT-related proteins mediate AKR1B10-induced proliferation and migration in BC cells.

\section{AKR1B10 activates the NF-KB pathway}

Previous studies have shown that NF-KB signaling plays a critical role in tumor cell progression[15]. Hence, we examined the phosphorylation levels of both IKBa and NF-KB p65 in AKR1B10-knockdown and overexpressed BC cells.

Overexpression of AKR1B10 significantly increased the phosphorylation of IKBa and NF-KB p65 compared to control cells (Fig. 3A), while knockdown of AKR1B10 markedly inhibited the phosphorylation of these molecules (Fig. 3B). As we know that NF-KB p65 is a nuclear transcription factor which enters the nucleus upon activation, we examined the nuclear expression of NF-KB p65 by western blotting in AKR1B10-knockdown BT-20 cells. As shown in Fig. 3C, knockdown of AKR1B10 reduced NF-KB p65 protein expression within the nucleus. This result was supported by immunofluorescence analysis, which showed an increased nuclear accumulation of NF-KB p65 in AKR1B10-overexpressed MCF-7 cells (Fig. 3D). Together, these results suggest that increased AKR1B10 activates the NF-KB signaling pathway.

\section{AKR1B10 activates PI3K/AKT pathway}

Recently, AKR1B10 has been reported to regulate phosphatidylinositol $(3,4)$-bisphosphate $\left(\mathrm{PIP}_{2}\right)$ expression in $\mathrm{BC}$ cells[6]. $\mathrm{PIP}_{2}$ is the substrate of phosphatidylinositol 3-kinase (PI3K)[16]. $\mathrm{PIP}_{3}$ is produced from $\mathrm{PIP}_{2}$ by activated PI3K[16]. Gene function analysis indicated that AKR1B10 was significantly associated with the terms 'positive regulation of protein kinase $B$ signaling' (data not shown). Based on these results, we first analyzed expression levels of $\mathrm{PIP}_{3}$ in $\mathrm{BC}$ cells. As shown in Fig. 4A-B, overexpression of AKR1B10 increased PIP ${ }_{3}$ expression levels in MCF-7 cells, while knockdown 
of AKR1B10 decreased PIP ${ }_{3}$ expression levels in BT-20 cells. These results suggest that AKR1B10 may be involved in regulating $\mathrm{PIP}_{3}$ synthesis. Next, we analyzed the phosphorylation and thus, activation, of PI3K/AKT signaling pathway-related proteins. Indeed, AKR1B10 overexpression increased the levels of phosphorylated-PI3K and phosphorylated-AKT, and not surprisingly, inhibition of AKR1B10 decreased the levels of these molecules in BC cells (Fig. 4C-D). These results suggest that the PI3K/AKT signaling pathway participates in AKR1B10-induced pathological progression in BC cells.

\section{PI3K/AKT-activated NF-KB signaling pathway contributes to the AKR1B10 function in BC}

Previous studies have shown that NF-KB expression is regulated by inhibitory IKB proteins, which can be regulated by the upstream PI3K/AKT signaling pathway. To test whether up-regulation in NF-KB p65 protein expression was due to activation of the PI3K/AKT signaling pathway, we used LY294002, a PI3K specific inhibitor. MCF-7/AKR1B10 cells were treated with $30 \mu \mathrm{M}$ and $50 \mu \mathrm{M}$ PI3K inhibitor for 48 hours. As anticipated, the levels of phosphorylated-PI3K and phosphorylated-AKT were significantly reduced in the presence of PI3K inhibitor (Fig. 5A). Surprisingly, we found that LY94002 inhibited the levels of phosphorylated-IKBa and total NF-KB p65 in MCF-7/AKR1B10 cells (Fig. 5A). However, the changes in phosphorylated-NF-KB p65 was not concomitant with a decrease in NF-KB p65 protein levels. Then we further detected the effects of PI3K inhibitor on NF-KB p65 nuclear translocation by using a nuclear/cytosol fractionation assay. Nuclear expression of NF-KB p65 was decreased after treatment with the PI3K inhibitor in MCF-7/AKR1B10 cells (Fig. 5B). Taken together, these results show that AKR1B10 activates the NF-KB signaling pathway, which can be inhibited by PI3K specific inhibitor LY94002. AKR1B10 may promote BC progression by activating the PI3K/AKT/NF-KB signaling cascade.

\section{Knockdown of AKR1B10 inhibits in vivo tumorigenesis}

Taking our study further, we investigated the effect of AKR1B10 knockdown on the growth of BC tumors in an in vivo mouse tumorigenesis model. Human BT-20/Scramble and BT-20/shAKR1B10 breast cancer cells were implanted orthotopically into nude mice mammary fat pads. About four weeks after inoculation, the nude mice were sacrificed, and tumors were collected and weighted. As shown in Fig. 6A$\mathrm{B}$, consistent with the results of the CCK8 assay, AKR1B10 knockdown significantly inhibited tumor growth in vivo. This suggests that higher expression levels of AKR1B10 in tumors are closely related to the proliferation of $\mathrm{BC}$ cells.

\section{Discussion}

Breast carcinoma is the most common malignant tumor in females $[1,17]$. According to statistics in China, $\mathrm{BC}$ accounts for $17 \%$ of all malignant tumors in women[2]. The metastasis of $\mathrm{BC}$ is one of the leading causes of poor prognosis in female patients. However, the mechanism of $\mathrm{BC}$ progression is complicated and further research on the underlying molecular mechanisms is warranted. 
As a member of aldehyde ketone reductase superfamily, AKR1B10 was first studied in lung cancer[18]. A few studies have shown that AKR1B10 is closely correlated with the progression of cancer. In oral squamous cell carcinoma[9, 19], non-small cell lung carcinoma[20] and liver carcinoma[7], high expression levels of AKR1B10 in patients is correlated with poor prognosis. Large-scale and multicenter studies have shown that AKR1B10 may serve as a serological markers for HCC in humans[10]. AKR1B10 plays a critical role in invasion and chemoresistance in BC cells[11]. In our study, we found that AKR1B10 is highly and specifically expressed in BC tissue. Elevated expression of AKR1B10 is correlated with clinicopathological features (e.g: tumor size, Ki67 expression, and p53 expression), negative overall survival rate and negative disease-free survival rate. Similar findings were also reported in another similar study[12]. More importantly, upregulated AKR1B10 was related with poor disease free survival in triplenegative BC, which further supports the critical role of AKR1B10 in breast cancer.

EMT is a biological process whereby epithelial-like cells transform into mesenchymal-like cells and gain migratory and metastatic potential[21]. EMT plays an important role during development including formation of the gastrointestinal system and neural tube formation, as well as in the wound-healing process[22]. Malignant progression of primary tumors highly depend on EMT[23-25]. In the present study, we show that overexpression of AKR1B10 enhances migration of BC cells in vitro, while knockdown decreases migration. The increased migratory potential could be attributed to decrease in Ecadherin expression upon AKR1B10 overexpression in MCF-7 cells. Further, we show that AKR1B10 regulates the expression of EMT-related transcription factors, including ZEB1, Snail, Slug and twist. These results demonstrate possible roles for AKR1B10 in the regulation of EMT. However, it should be noted that knockdown of AKR1B10 in BT-20 cells did not result in significant changes in all EMT-related transcription factors. Taking into account the heterogeneity of tumor cells, some differences in the activation of EMT induced by AKR1B10 can be expected. Abnormal proliferation is one of the hallmarks of tumorigenesis. Cell growth-related factors, including c-myc, cyclinD1 and survivin, constitute an important group of molecules that regulate cell proliferation in tumor cells[26]. In our study, we demonstrate elevated expression of AKR1B10 in MCF-7 cells upregulates cyclinD1, c-Myc and survivin, while knockdown of AKR1B10 in BT-20 cells downregulates these molecules. Taken together, we show that AKR1B10 regulates different genes known to regulate $\mathrm{BC}$ migration and proliferation.

The PI3K/AKT signaling pathway is involved in various cellular processes such as glucose metabolism, apoptosis, cell proliferation, and cell migration[16, 27, 28]. Sustained activation of EMT has been reported to be regulated by the PI3K/AKT signaling pathway in numerous cancers. For example, cPLA2a has been shown to mediate EMT via the PI3K/AKT pathway[29]. Previous studies suggest that $\mathrm{PIP}_{2}$ is upregulated in BC cells in which AKR1B10 is overexpressed[6], which prompted us to investigate the phosphatidylinositol and PI3K/AKT pathway in detail. Consistently, our study demonstrated that the $\mathrm{PI3K} / \mathrm{AKT}$ pathway was up-regulated in AKR1B10-induced BC progression. Further, studies have shown that activation of the PI3K/AKT pathway is also involved in activation of NF-KB via phosphorylation of inhibitory IKBa[30]. Our results showed that LY294002, a specific PI3K inhibitor, suppressed NF-KB p65 nuclear localization, which indicates that the activation of the PI3K/AKT/NF-KB signaling cascade is 
regulated by AKR1B10. CyclinD1, c-myc, survivin and EMT-related proteins are downstream intracellular signal molecules for NF-KB signaling[26, 31]. Thus, AKR1B10 may regulate proliferation-related and EMTrelated proteins via the PI3K/AKT/NF-KB signaling cascade. Another study has shown that AKR1B10 can promote proliferation and migration/invasion of breast cancer cells via the ERK and FAK/Src/Rac1 signaling pathway $[8,32]$. Several studies have also demonstrated that PI3K/AKT and MEK/ERK signaling pathways can be activated in tumors together[33-35]. AKR1B10 may affect several signaling pathways in BC. However, it should be noted that high expression of AKR1B10 induces cell cycle arrest in HeLa cells. Also, evidence of high expression levels of AKR1B10 in some normal tissues such as colon tissue[5], suggests that AKR1B10 regulation of cell proliferation and migration may be context dependent.

In conclusion, the present study demonstrates that elevated expression levels of AKR1B10 expression in $\mathrm{BC}$ tissues correlates with poor prognosis. AKR1B10, as a critical onco-protein, may activate the $\mathrm{PI} 3 \mathrm{~K} / \mathrm{AKT} / \mathrm{NF}-\mathrm{KB}$ signaling cascade to promote the expression of proliferation-related and EMT-related proteins and consequently promote the proliferation and migration in BC cells. Thus, AKR1B10 might serve as a new prognostic indicator and a potential therapeutic target for BC.

\section{Abbreviations}

AKR1B10, Aldo-Keto reductase family 1 member B10; BC, breast cancer; GO, Gene Ontology; ARL-1, Aldose reductase like protein-1; ELISA, enzyme-linked immunosorbent assay; IHC, immunohistochemistry; EMT, Epithelial-mesenchymal transition; ERK, extracellular-signal-regulated kinase.

\section{Declarations}

\section{Ethics approval and consent to participate}

The study was approved by the local Ethic Committee.

\section{Consent for publication}

All the listed authors have participated in the study, and have seen and

\section{Availability of data and materials}

All the data and material could be traced from the paper or can be requested from the corresponding author.

\section{Competing interests}

The authors declare that they have no competing interests. 


\section{Funding}

This work was supported by the Hunan Province Science Fund for Distinguished Young Scholars (No.2018JJ1021); the Key R\&D Program of Hunan Province (2017SK2172); the Natural Science Foundation of Hunan Province (No.2017JJ2003, 2017JJ2004, 2019JJ50022, 2020JJ5013); the Hunan Province Technological Innovation Guiding Plan, Clinical Medical Technology Innovation Guidance Project (2017SK51101); the Health Department project of the Hunan Province (No.B2017182, B20180378, B20180266, B2019001, C2019003); the Education Department project of Hunan Province (No.18C0066); and the Science and Technique Foundation of Chenzhou (jsyf2017021, zdyf201837, zdyf201840); the Science Foundation of XiangNan University (2016XJ71, 2017XJ48, 2017XJ49, 2017XJ50); the Science Foundation of The First People's Hospital of Chenzhou (N2019-009, N2020-3)

\section{Author contributions}

$\mathrm{DL}$ and $\mathrm{ZH}$ designed the experiments. JQ, JL, RH, XL, KG, WL, LD, performed the experiments and analyzed the corresponding results. JQ and DL wrote the manuscript. All authors read and approved the inal manuscript.

\section{Acknowledgements}

Not applicable.

\section{References}

1. Siegel RL, Miller KD, Jemal A. Cancer statistics, 2019. CA Cancer J Clin. 2019;69:7-34.

2. Li T, Mello-Thoms C, Brennan PC. Descriptive epidemiology of breast cancer in China: incidence, mortality, survival and prevalence. Breast Cancer Res Treat. 2016;159:395-406.

3. Foulkes WD, Smith IE, Reis-Filho JS. Triple-negative breast cancer. N Engl J Med. 2010;363:1938-48.

4. Waks AG, Winer EP. Breast Cancer Treatment JAMA. 2019;321:316.

5. Zhong L, Liu Z, Yan R, Johnson S, Zhao Y, Fang X, et al. Aldo-keto reductase family 1 B10 protein detoxifies dietary and lipid-derived alpha, beta-unsaturated carbonyls at physiological levels. Biochem Biophys Res Commun. 2009;387:245 - 50.

6. Huang C, Cao Z, Ma J, Shen Y, Bu Y, Khoshaba R, et al. AKR1B10 activates diacylglycerol (DAG) second messenger in breast cancer cells. Mol Carcinog. 2018;57:1300-10.

7. DiStefano JK, Davis B. Diagnostic and Prognostic Potential of AKR1B10 in Human Hepatocellular Carcinoma. Cancers (Basel). 2019;11.

8. Li J, Guo Y, Duan L, Hu X, Zhang X, Hu J, et al. AKR1B10 promotes breast cancer cell migration and invasion via activation of ERK signaling. Oncotarget. 2017;8:33694-703. 
9. Ko HH, Peng HH, Cheng SJ, Kuo MY. Increased salivary AKR1B10 level: Association with progression and poor prognosis of oral squamous cell carcinoma. Head Neck. 2018;40:2642-7.

10. Ye X, Li C, Zu X, Lin M, Liu Q, Liu J, et al. A Large-Scale Multicenter Study Validates Aldo-Keto Reductase Family 1 Member B10 as a Prevalent Serum Marker for Detection of Hepatocellular Carcinoma. Hepatology. 2019;69:2489 - 501.

11. Zhong $L$, Shen $H$, Huang $C$, Jing $H$, Cao D. AKR1B10 induces cell resistance to daunorubicin and idarubicin by reducing C13 ketonic group. Toxicol Appl Pharmacol. 2011;255:40 - 7.

12. Ma J, Luo DX, Huang C, Shen Y, Bu Y, Markwell S, et al. AKR1B10 overexpression in breast cancer: association with tumor size, lymph node metastasis and patient survival and its potential as a novel serum marker. Int J Cancer. 2012;131:E862-71.

13. Yang S, Kim CY, Hwang S, Kim E, Kim H, Shim H, et al. COEXPEDIA: exploring biomedical hypotheses via co-expressions associated with medical subject headings (MeSH). Nucleic Acids Res. 2017;45:D389-389D396.

14. Wang Q, He R, Tan T, Li J, Hu Z, Luo W, et al. A novel long non-coding RNA-KAT7 is low expressed in colorectal cancer and acts as a tumor suppressor. Cancer Cell Int. 2019;19:40.

15. Zhang Q, Lenardo MJ, Baltimore D. 30 Years of NF-KB: A Blossoming of Relevance to Human Pathobiology. Cell. 168:37-57.

16. Manning BD, Toker A. AKT/PKB Signaling: Navigating the Network. Cell. 2017;169:381-405.

17. Bray F, Ferlay J, Soerjomataram I, Siegel RL, Torre LA, Jemal A. Global cancer statistics 2018: GLOBOCAN estimates of incidence and mortality worldwide for 36 cancers in 185 countries. CA Cancer J Clin. 2018;68:394-424.

18. Kim B, Lee HJ, Choi HY, Shin Y, Nam S, Seo G, et al. Clinical validity of the lung cancer biomarkers identified by bioinformatics analysis of public expression data. Cancer Res. 2007;67:7431-8.

19. Fang $\mathrm{CY}$, Lin $\mathrm{YH}$, Chen $\mathrm{CL}$. Overexpression of AKR1B10 predicts tumor recurrence and short survival in oral squamous cell carcinoma patients. J Oral Pathol Med. 2019;48:712-9.

20. Zhou Z, Zhao Y, Gu L, Niu X, Lu S. Inhibiting proliferation and migration of lung cancer using small interfering RNA targeting on Aldo-keto reductase family 1 member B10. Mol Med Rep. 2018;17:215360.

21. Lamouille S, Xu J, Derynck R. Molecular mechanisms of epithelial-mesenchymal transition. Nat Rev Mol Cell Biol. 2014;15:178 - 96.

22. Thiery JP, Acloque H, Huang RY, Nieto MA. Epithelial-mesenchymal transitions in development and disease. Cell. 2009;139:871 - 90.

23. Nisticò P, Bissell MJ, Radisky DC. Epithelial-mesenchymal transition: general principles and pathological relevance with special emphasis on the role of matrix metalloproteinases. Cold Spring Harb Perspect Biol. 2012;4.

24. Lim J, Thiery JP. Epithelial-mesenchymal transitions: insights from development. Development. 2012;139:3471-86. 
25. Dongre A, Weinberg RA. New insights into the mechanisms of epithelial-mesenchymal transition and implications for cancer. Nat Rev Mol Cell Biol. 2019;20:69-84.

26. Yang Z, Li C, Wang X, Zhai C, Yi Z, Wang L, et al. Dauricine induces apoptosis, inhibits proliferation and invasion through inhibiting NF-kappaB signaling pathway in colon cancer cells. J Cell Physiol. 2010;225:266 - 75 .

27. Yang J, Nie J, Ma X, Wei Y, Peng Y, Wei X. Targeting PI3K in cancer: mechanisms and advances in clinical trials. Mol Cancer. 2019;18:26.

28. Hoxhaj G, Manning BD. The PI3K-AKT network at the interface of oncogenic signalling and cancer metabolism. Nat Rev Cancer. 2020;20:74-88.

29. Chen L, Fu H, Luo Y, Chen L, Cheng R, Zhang N, et al. cPLA2a mediates TGF- $\beta$-induced epithelialmesenchymal transition in breast cancer through PI3k/Akt signaling. Cell Death Dis. 2017;8:e2728.

30. Shao N, Lu Z, Zhang Y, Wang M, Li W, Hu Z, et al. Interleukin-8 upregulates integrin $\beta 3$ expression and promotes estrogen receptor-negative breast cancer cell invasion by activating the PI3K/Akt/NF-KB pathway. Cancer Lett. 2015;364:165 - 72.

31. Yang Z, Zhang C, Qi W, Cui Y, Xuan Y. GLI1 promotes cancer stemness through intracellular signaling pathway PI3K/Akt/NFKB in colorectal adenocarcinoma. Exp Cell Res. 2018;373:145 - 54.

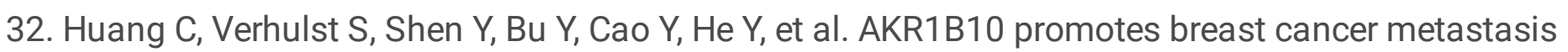
through integrin a5/ $\delta$-catenin mediated FAK/Src/Rac1 signaling pathway. Oncotarget. 2016;7:4377991.

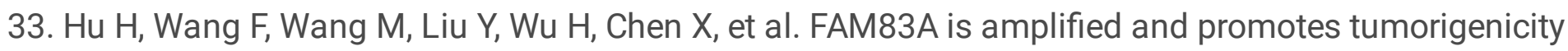
in non-small cell lung cancer via ERK and PI3K/Akt/mTOR pathways. Int J Med Sci. 2020;17:807 14.

34. Peng X, Liu Y, Zhu S, Peng X, Li H, Jiao W, et al. Co-targeting PI3K/Akt and MAPK/ERK pathways leads to an enhanced antitumor effect on human hypopharyngeal squamous cell carcinoma. $J$ Cancer Res Clin Oncol. 2019;145:2921-36.

35. Wu YL, Maachani UB, Schweitzer M, Singh R, Wang M, Chang R, et al. Dual Inhibition of PI3K/AKT and MEK/ERK Pathways Induces Synergistic Antitumor Effects in Diffuse Intrinsic Pontine Glioma Cells. TransI Oncol. 2017;10:221-8.

\section{Figures}


Fig1

A

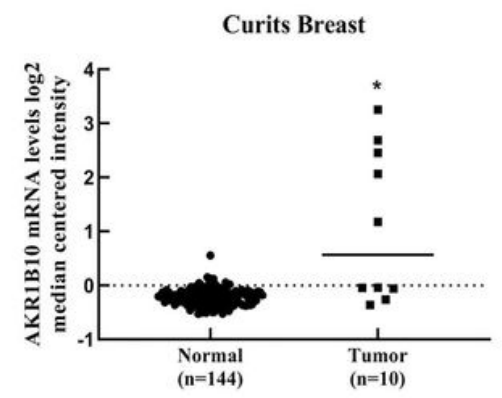

D

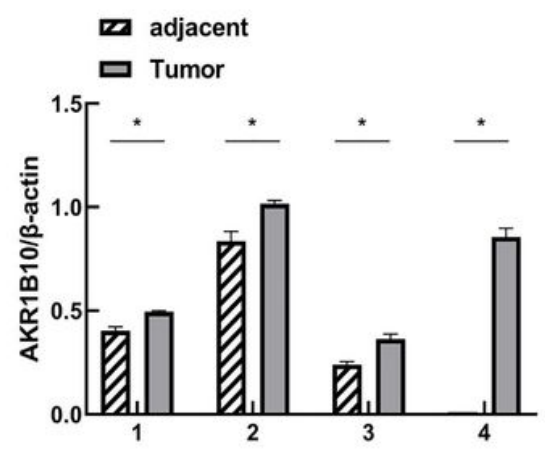

G

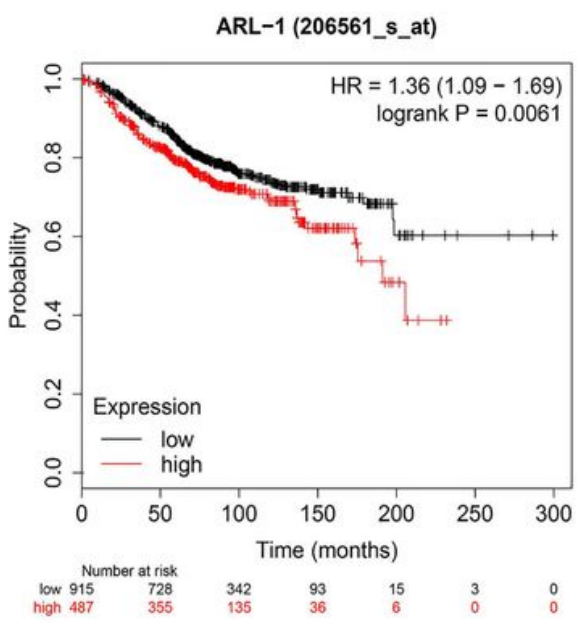

B

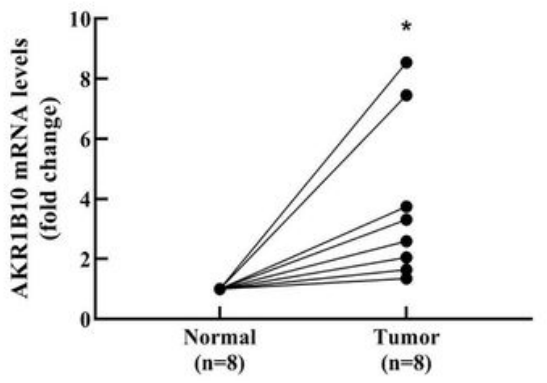

E

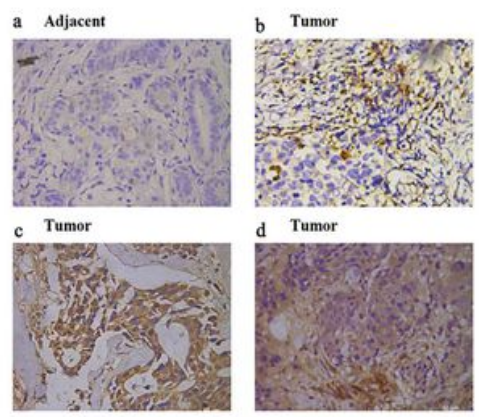

H

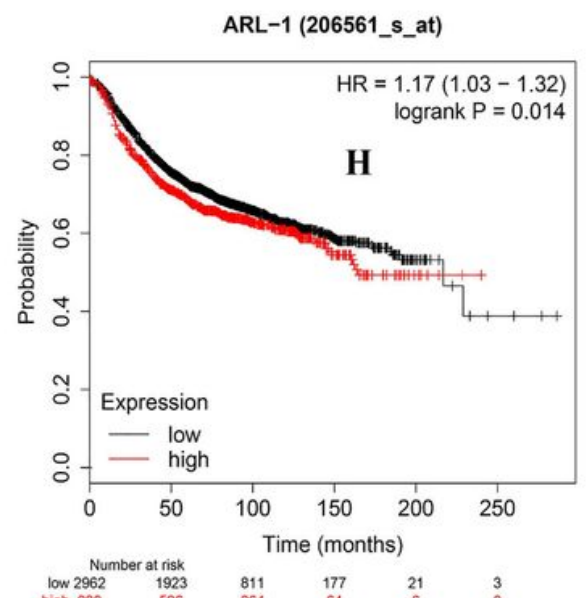

C

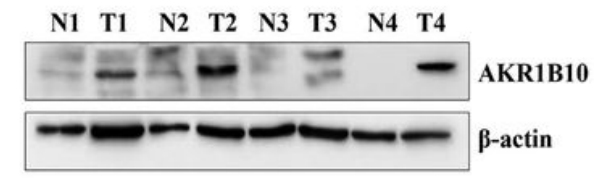

F

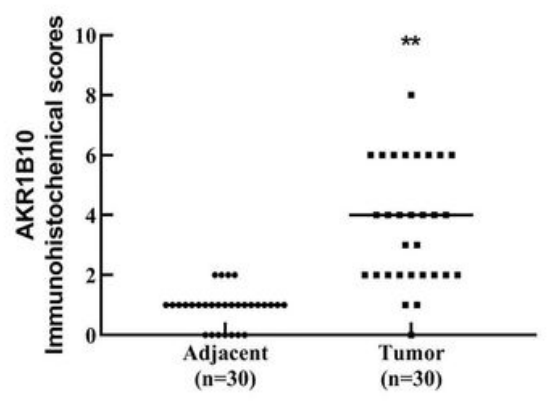

I

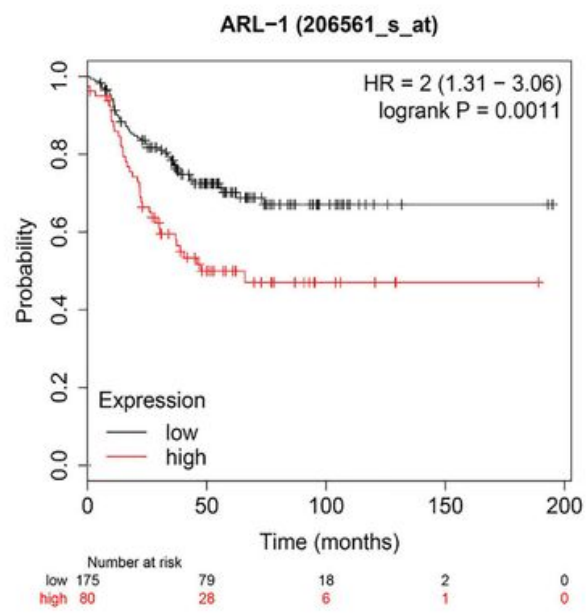

\section{Figure 1}

AKR1B10 is highly expressed in breast cancer tissues and correlates with patient prognosis. (A) AKR1B10 mRNA was upregulated in cancerous tissue compared to normal tissue in Curits Breast dataset; (B) AKR1B10 mRNA was higher in 8 fresh breast tumor specimens than in paired adjacent normal tissue. The AKR1B10 relative expression levels were normalized to 1 in adjacent normal tissue; (C-D) AKR1B10 protein levels were higher in 4 fresh $\mathrm{BC}$ tissues than in adjacent normal tissues, data quantification relative to $\beta$-actin levels were compared for AKR1B10. (E-F) The immunohistochemical staining (IHC) 
score of AKR1B10 in cancerous tissue was significantly higher than the scores in adjacent normal tissues. Scale bar $=50 \mu \mathrm{m}$; (G-H) Kaplan-Meier estimation revealed significantly lower overall and diseasefree survival rates in patients with AKR1B10high BC than that in AKR1B10low patients; (I) Data in KMPLOT database showed that AKR1B10high patients had significantly disease-free survival rates than that in AKR1B10low in triple negative BC patients.

Fig 2

A

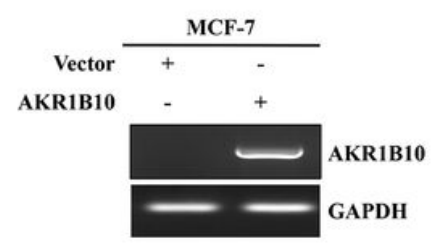

B

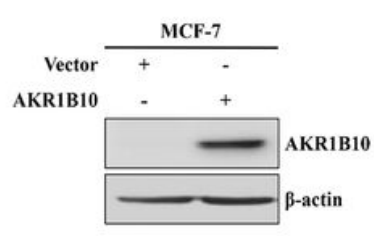

C

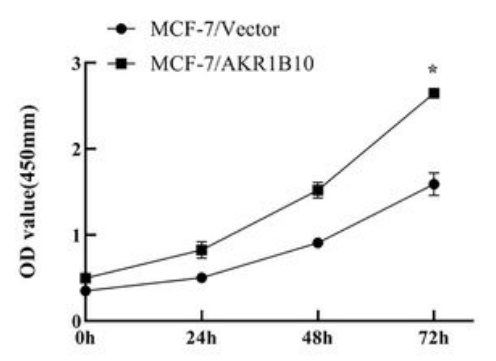

E

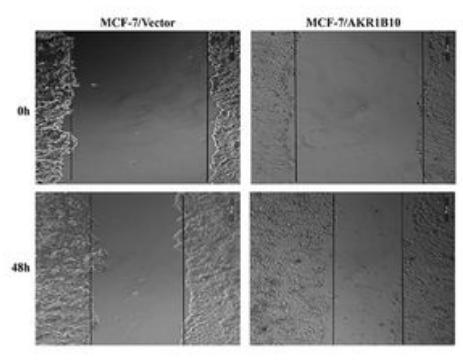

G

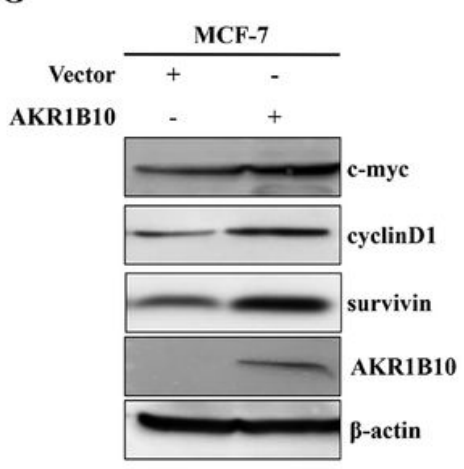

D

F

H

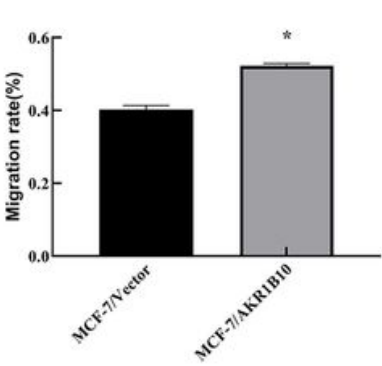

I
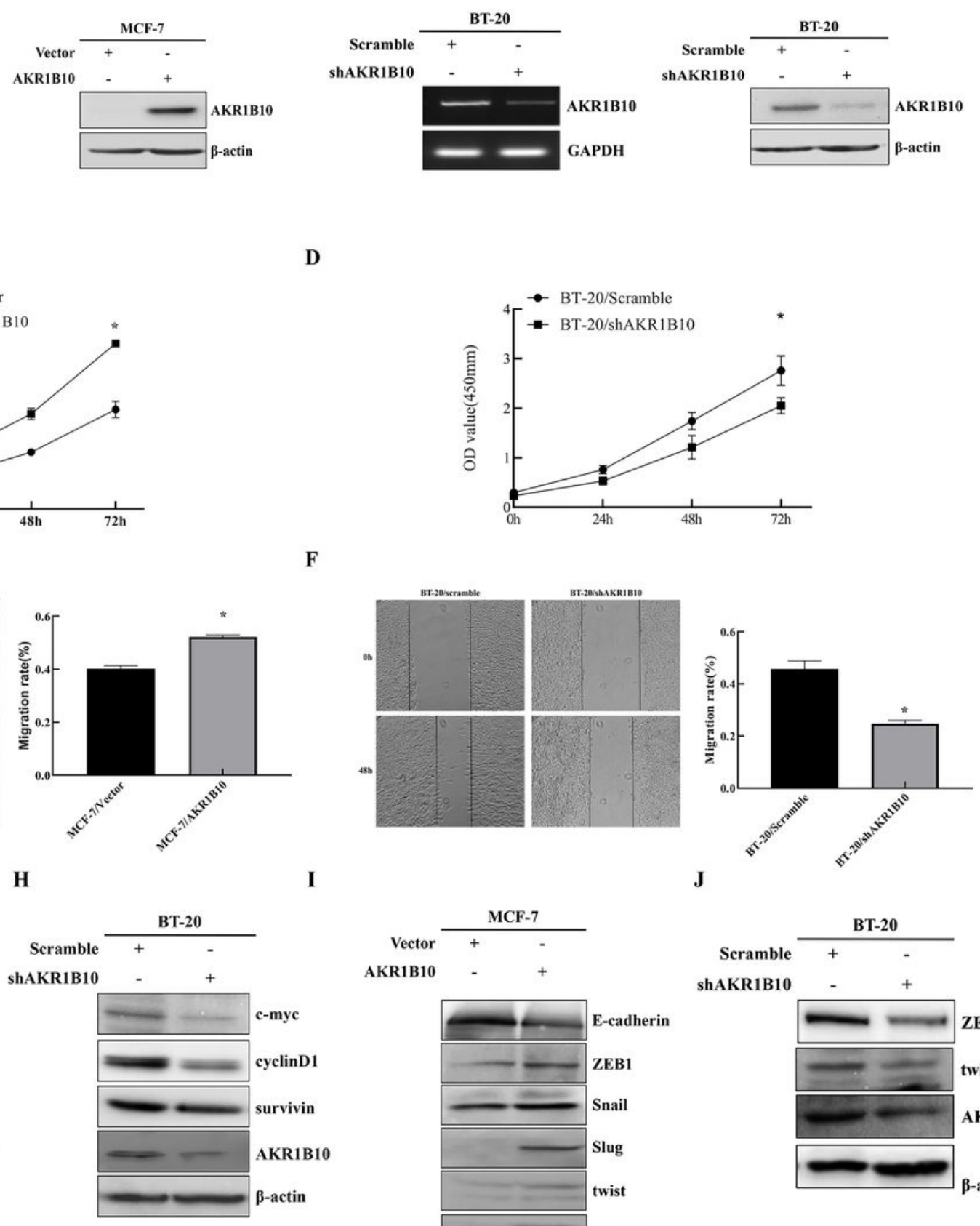

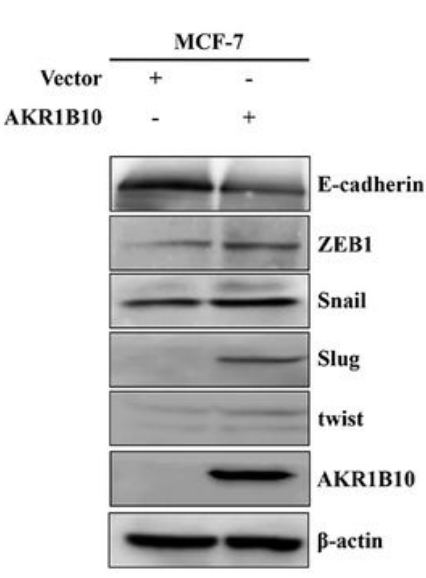

$\mathbf{J}$

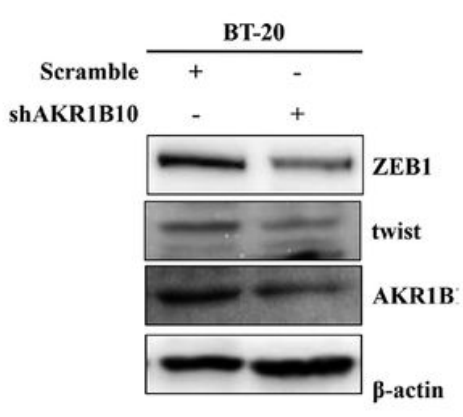

Figure 2 
AKR1B10 promotes the proliferation and migration of BC cells in vitro via regulation of epithelialmesenchymal transition (EMT) and proliferation -related genes (A-B) RT-PCR and western blot analysis of gene expression changes upon AKR1B10 overexpression and knockdown in MCF-7 cells and BT-20 cells, respectively; (C-D) AKR1B10 overexpression increased cell proliferation in MCF-7 cells and AKR1B10 knockdown inhibited cell proliferation in BT-20 cells; (E-F) MCF-7 cell migration was significantly enhanced when AKR1B10 was overexpressed while BT-20 cell migration was significantly inhibited when AKR1B10 was knocked down in a scratch wound assay; (G-H) Western blotting analysis showed increased protein levels of c-myc, cyclinD1, and survivin in MCF-7/AKR1B10 cells, and reduced protein levels in BT-20/sh-AKR1B10 cells, respectively; (I) Western blotting analysis showed significantly upregulated ZEB1, Snail, Slug, twist and downregulated E-cadherin in MCF-7/AKR1B10 cells compared to vector control cells; $(\mathrm{J})$ Western blotting analysis showed significantly reduced ZEB1, twist at protein level in BT-20/sh-AKR1B10 cells compared to scramble control cells. ${ }^{*} \mathrm{P}<0.05$ 
${ }^{\text {Fig }}{ }^{3}$

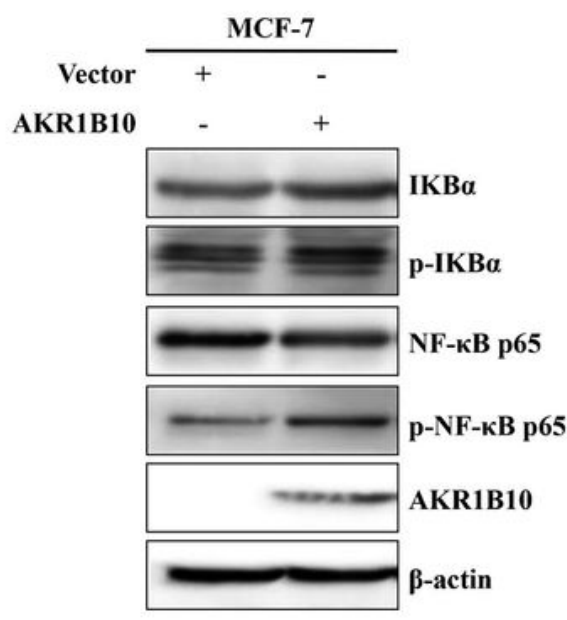

C

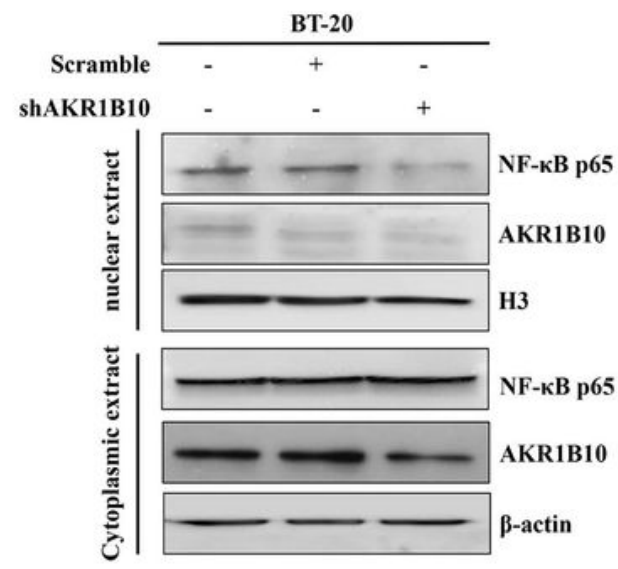

E

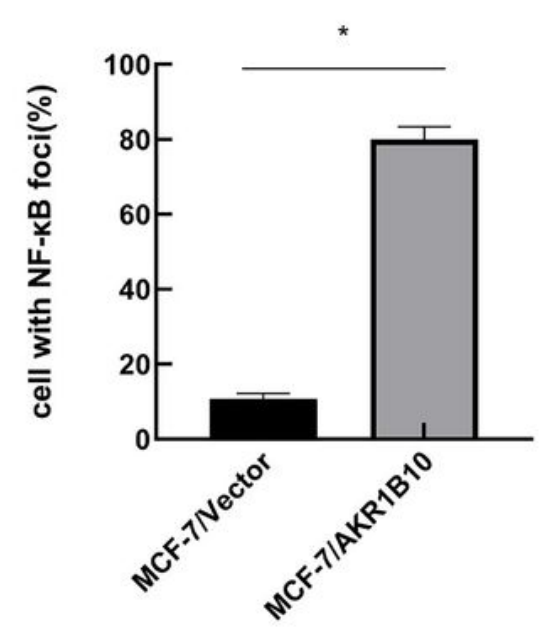

B

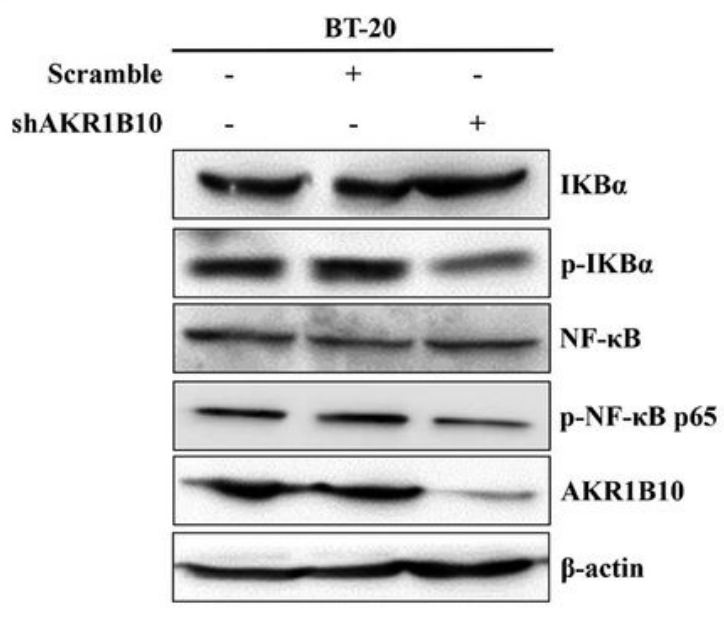

D

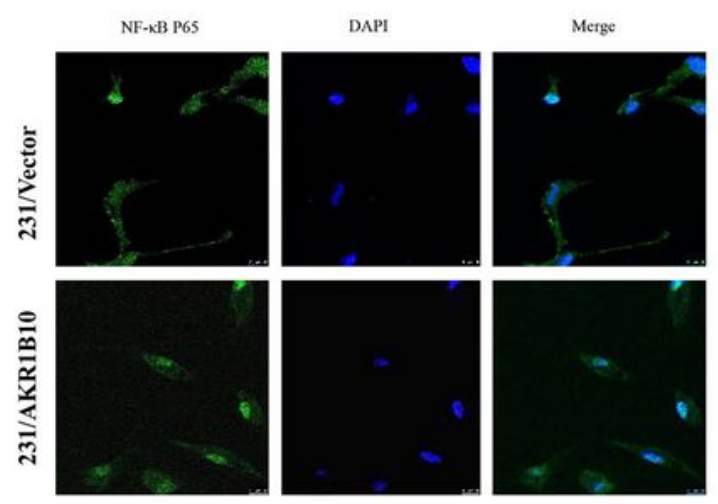

\section{Figure 3}

AKR1B10 activates the NF-KB pathway in BC cells. (A-B) Western blotting analysis showed increased protein levels of Phosphorylated-IKBa and Phosphorylated-NF-KB p65 in MCF-7/AKR1B10 cells, and reduced protein levels of Phosphorylated-IKBa and Phosphorylated-NF-KB p65 in BT-20 cells/sh-AKR1B10 cells, respectively; (C) Western blotting analysis showed decreased protein levels of nuclear NF-KB p65 in nucleus in BT-20/sh-AKR1B10 cells; (D-E) Immunofluorescence colocalization experiments showed 
enhanced nuclear translocation of NF-KB p65 in MCF-7/AKR1B10 cells compared to vector control cells. *P<0.05; ** $\mathrm{P}<0.01$

Fig4

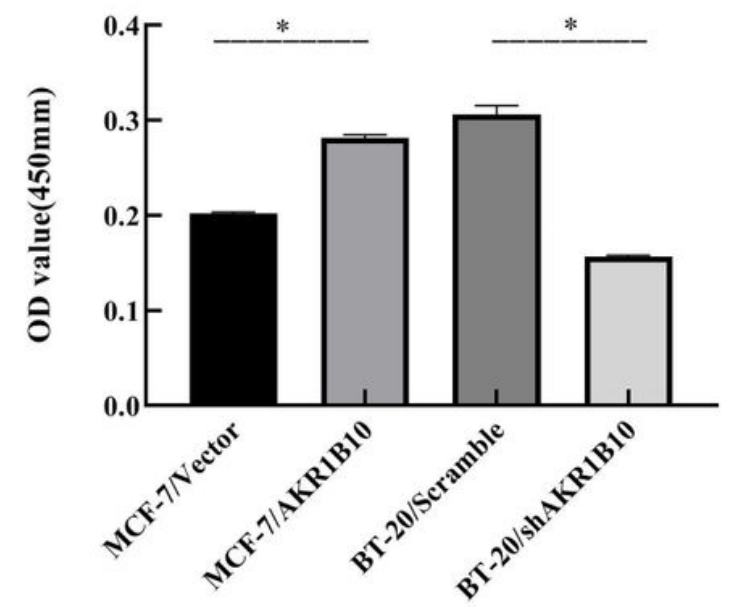

C

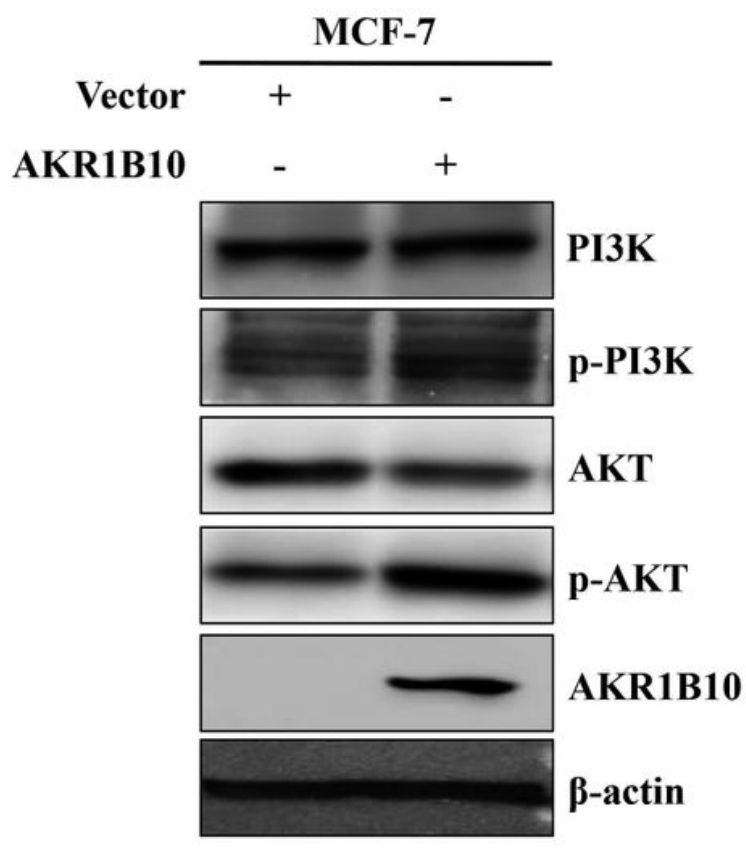

B

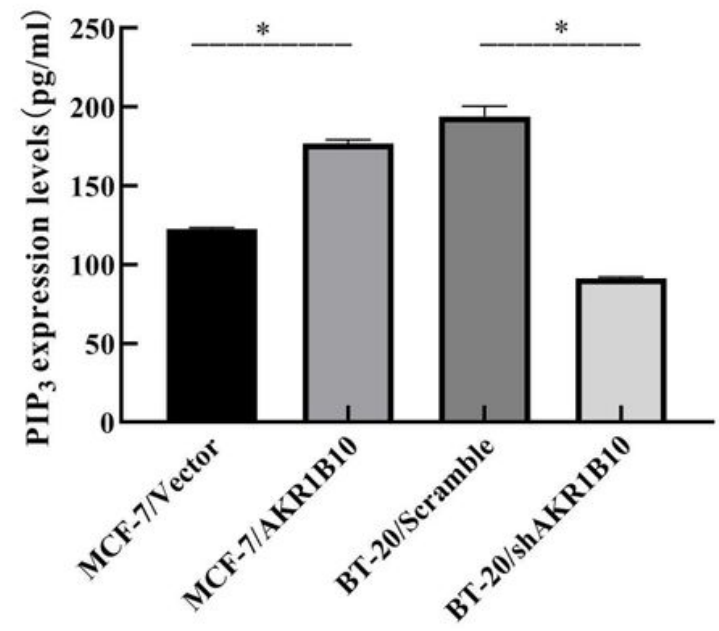

D

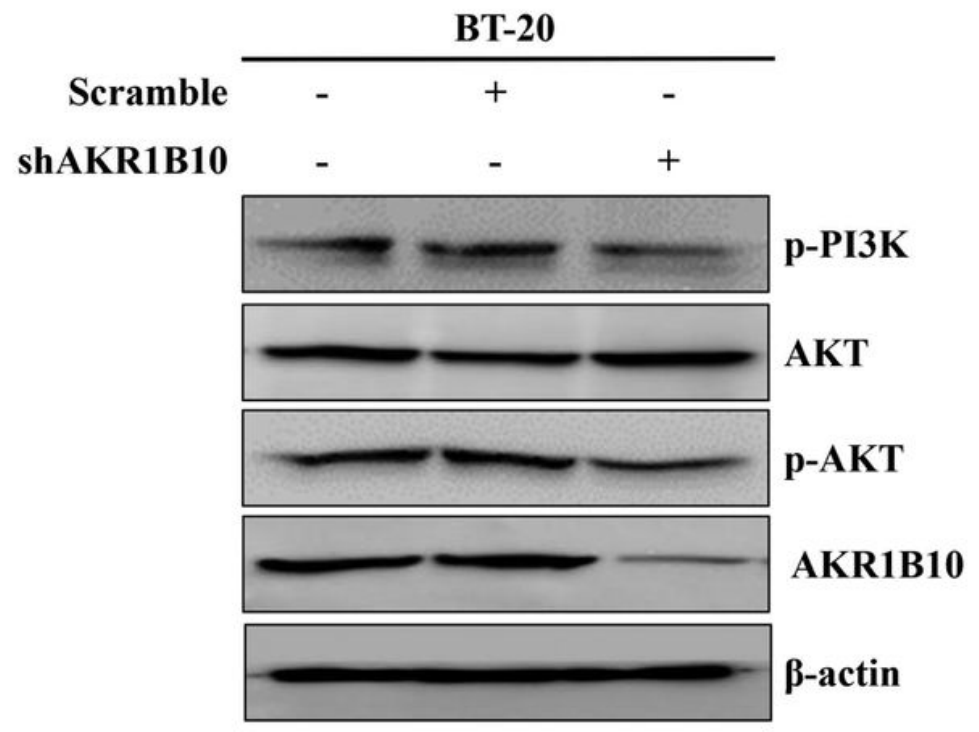

Figure 4

AKR1B10 promotes PIP3 expression and subsequent activation of the PI3K/AKT pathway in BC cells. (AB) PIP3 ELISA kit analysis showed increased expression levels of PIP3 in MCF-7/AKR1B10 cells, and reduced expression levels of PIP3 in BT-20/sh-AKR1B10 cells, respectively; (C-D) Western blotting analysis showed increased protein levels of Phosphorylated-PI3K and Phosphorylated-AKT in MCF7/AKR1B10 cells, and reduced protein levels of Phosphorylated-PI3K and Phosphorylated-AKT in BT20/sh-AKR1B10 cells, respectively. ${ }^{*} \mathrm{P}<0.05$ 


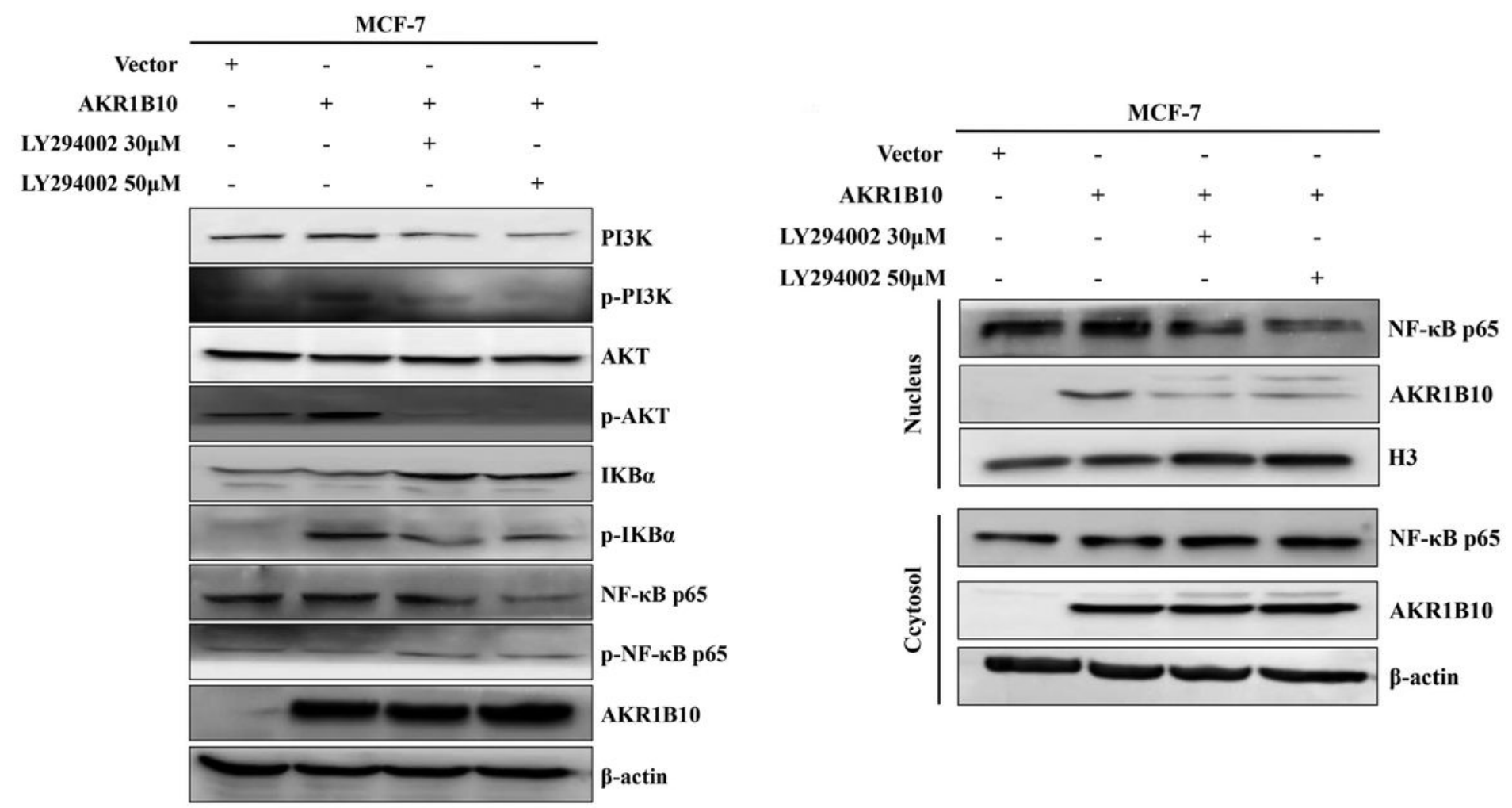

\section{Figure 5}

Nuclear translocation of NF-KB p65 was inhibited by PI3K inhibition. (A) Western blotting analysis showed that treatment with LY294002 $(30 \mu \mathrm{M}, 50 \mu \mathrm{M})$ attenuated AKR1B10-induced Phosphorylated-PI3K, Phosphorylated-AKT; Phosphorylated-IKBa in MCF-7/AKR1B10 cells; (B) Western blotting analysis showed that treatment with LY294002 $(30 \mu \mathrm{M}, 50 \mu \mathrm{M})$ attenuated AKR1B10-incuded expression of nuclear NF-KB p65. *P<0.05 
Fig 6

A

BT-20/Scramble

BT-20/shAKR1B10
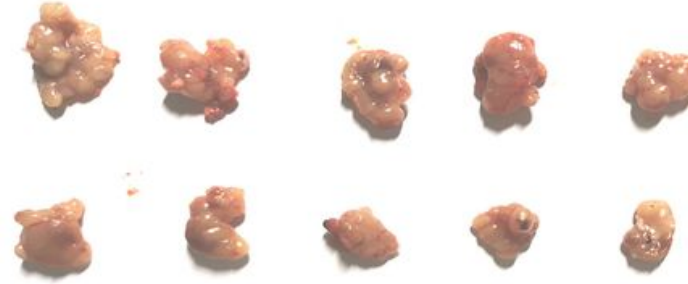
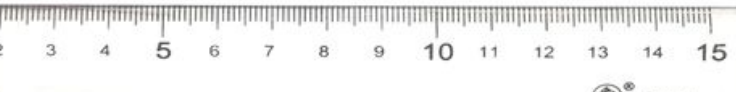

(9) YS-8015

\section{Figure 6}

AKR1B10 knockdown inhibits BT-20 tumorigenesis in vivo. (A-B) AKR1B10 knockdown inhibited the growth of BT-20 cells in vivo, compared to scramble control-injected cells.

\section{Supplementary Files}

This is a list of supplementary files associated with this preprint. Click to download.

- TableS1.doc

- AKR1B10coverletterCCIN.docx 